Atividades grupais para trabalhadores com distúrbios osteomusculares relacionados ao trabalho: relato de experiência

\title{
Group activities for workers with musculoskeletal disorders associated to work: an experience report
}

\section{Actividades grupales para trabajadores con disturbios osteomusculares relacionados} al trabajo: relato de experiencia

Recebido: 01/12/2019

Aprovado: 23/04/2019

Publicado: 15/05/2020

\section{Alline Alves de Sousa ${ }^{1}$ Thais de Souza Toledo ${ }^{2}$ Edneia de Oliveira Salum ${ }^{3}$ Jéssica Carvalho Lima ${ }^{4}$ Camila Soares ${ }^{5}$} Isabel Aparecida Porcatti de Walsh ${ }^{6}$

Este é um estudo descritivo, com o objetivo de relatar as experiências de atividade grupal com trabalhadores com Lesões por Esforços Repetitivos / Distúrbio Osteomusculares Relacionados ao Trabalho, realizado no segundo semestre de 2019. Participaram seis trabalhadores, com idades variando entre 49 e 62 anos $(55,16 \pm 4,45)$, sendo cinco $(83,3 \%)$ mulheres. Entre os relatos associados ao sofrimento destacam-se as dores crônicas intensas que contribuem para o surgimento de medo, angústia, ansiedade e depressão. As intervenções indicaram que a abordagem grupal permitiu o compartilhamento dos sentimentos e fortaleceram as relações de confiança entre os trabalhadores e os profissionais, possibilitando a criação de estratégias individuais e coletivas para o enfrentamento do sofrimento.

Descritores: Trabalhadores; Transtornos traumáticos cumulativos; Saúde do trabalhador.

This is a descriptive study, whose objective is to discuss the experiences of group activities involving workers with Repetitive Strain Injuries/Work-related Musculoskeletal Disorders. The research was carried out in the second half of 2019. Six workers participated, with ages varying between 49 and 62 years old $(55.16 \pm 4.45)$. Five $(83.3 \%)$ were women. Among the statements associated with suffering, there are intense chronic pains that contribute to the emergence of fear, anguish, anxiety, and depression. The interventions indicated that the use of collective groups allowed the sharing of feelings and strengthened the relationships of trust between workers and professionals, enabling the creation of individual and collective strategies for coping with suffering. Descriptores: Workers; Cumulative trauma disorders; Occupational health.

Este es un estudio descriptivo, con el objetivo de relatar las experiencias de actividad grupal con trabajadores con Lesiones por Esfuerzos Repetitivos / Disturbio Osteomusculares Relacionados al Trabajo, realizado en el segundo semestre de 2019. Participaron seis trabajadores, con edades variando entre 49 y 62 años $(55,16 \pm 4,45)$, siendo cinco $(83,3 \%)$ mujeres. Entre los relatos asociados al sufrimiento se destaca el dolor crónico intenso que contribuye al surgimiento de miedo, angustia, ansiedad y depresión. Las intervenciones indicaron que el abordaje grupal permitió compartir sentimientos y fortaleció las relaciones de confianza entre los trabajadores y los profesionales, posibilitando la creación de estrategias individuales y colectivas para el enfrentamiento del sufrimiento.

Descritores: Trabalhadores; Transtornos traumáticos cumulativos; Saúde do trabalhador.

\footnotetext{
1. Psicóloga. Doutora em Psicologia Organizacional e do Trabalho. Professora Adjunta da Universidade Federal do Espírito Santo. Vitória, ES, Brasil. ORCID: 0000-0002-4643-8089 E-mail: allineasouza@hotmail.com

2. Fisioterapeuta. Mestranda do Programa de Pós-Graduação em Fisioterapia (PPGF) pela Universidade Federal do Triângulo Mineiro (UFTM)/Universidade Federal de Uberlândia (UFU), Uberaba, MG, Brasil. ORCID: 0000-0002-8530-5764 E-mail: thast@hotmail.com

3. Fisioterapeuta. Especialista em Fisioterapia do Trabalho e Ergonomia. Especialista em Fisioterapia Dermatofuncional. Mestranda do PPGF/UFTM/UFU, Uberaba, MG, Brasil. ORCID: 0000-0003-2342-9400 E-mail: edneiasalum@hotmail.com

4. Fisioterapeuta. Mestranda do PPGF/UFTM/UFU, Uberaba, MG, Brasil. ORCID: 0000-0003-0972-1886 E-mail: jcarvalho.fisio.uftm@hotmail.com

6. Fisioterapeuta. Especialista em Fisioterapia Dermatofuncional. Mestranda do PPGF/ UFTM/UFU, Uberaba, MG, Brasil. ORCID: 0000-0002-2076-0758 E-mail: soarescamila.sp@gmail.com

7. Fisioterapeuta. Doutora em Fisioterapia. Professora Associada do curso de Graduação em Fisioterapia da UFTM e do PPGF/UFTM/UFU Uberaba, MG, Brasil. ORCID: 0000-0002-2317-1326 E-mail: isabelpwalsh@gmail.com
} 


\section{INTRODUÇÃO}

A s recentes transformações no mundo do trabalho podem ocasionar o aumento do desgaste físico e mental do trabalhador. Os modos de organização do trabalho, a gestão com cobranças excessivas, bem como o assédio moral, a falta de reconhecimento no trabalho, os conflitos de papeis e a percepção de injustiça no ambiente laboral geram sofrimento mental que influencia nos processos de adoecimento que afetam o sistema osteomuscular e que, no Brasil, são conhecidos como Lesões por Esforços Repetitivos/Distúrbios Osteomusculares Relacionados ao Trabalho (LER/DORT) ${ }^{1,2}$.

As LER/DORT podem ser caracterizadas como um grupo de agravos do sistema osteomuscular desenvolvidos durante a atividade laboral, desencadeados por um processo crônico de acometimento de músculos, tendões, articulações, nervos e ligamentos, resultando em queixas de dor, formigamento, dormência e fadiga ${ }^{3}$. Estão entre as principais causas de incapacidade temporária e permanente para o trabalho, gerando custos econômicos crescentes na área da saúde pública com a reabilitação desses trabalhadores ${ }^{4}$.

O sofrimento mental do portador de LER/DORT envolve múltiplos fatores contributivos, dentre eles: o preconceito, tendo em vista que a doença é mal vista na sociedade, sendo associada à preguiça, à incapacidade para o trabalho que provoca o afastamento do indivíduo de suas atividades usuais e de seu convívio social causando prejuízos à autoestima. Ainda, o estabelecimento de metas exacerbadas pelas organizações provoca, por sua vez, ameaças constantes de perda do emprego, que geram sentimentos de insegurança no trabalhador 5,6 . Consequentemente, a depressão é frequentemente tratada como comorbidade da LER/DORT 7 .

Assim, há um número considerável de trabalhadores afastados por LER/DORT e por transtornos mentais relacionados ao trabalho, tornando necessário que políticas públicas sejam pensadas e executadas no campo da saúde do trabalhador. Nesta conjuntura, os Centros de Referência em Saúde do Trabalhador (CEREST) devem assumir a função de prover suporte técnico e científico em saúde do trabalhador, coordenando projetos de promoção, vigilância e assistência à saúde dos trabalhadores, no âmbito de sua área de abrangência, a partir de uma cooperação técnica interinstitucional ${ }^{8}$.

Destaca-se que a universidade pode ser uma importante parceira dos CEREST, tendo em vista que as instituições de ensino superior devem buscar estreitar as relações com a comunidade, construindo elementos que permitam que os seus alunos possam vivenciar os desafios enfrentados na área da saúde pública cotidianamente ${ }^{9}$ e contribuindo para o desenvolvimento de projetos inovadores capazes de lidar com a complexidade que envolve a área da saúde do trabalhador ${ }^{10}$. As instituições de ensino superior têm o potencial de induzir o processo formativo dos profissionais, além de contribuir para o fortalecimento da saúde pública brasileira, e o SUS, por sua vez, pode oferecer para a comunidade acadêmica um amplo cenário com infinitas possibilidades de aprendizagem contínua.

Nesse sentido, a partir do ano de 2016, o CEREST/Regional Uberaba e o Curso de Fisioterapia da Universidade Federal do Triângulo Mineiro (UFTM) estabeleceram uma parceria, visando desenvolver ações em saúde do trabalhador.

Ao longo dessa parceria, a equipe responsável por essas ações conjuntas verificou alto número de usuários encaminhados pela rede de atenção à saúde do município aguardando chamadas para tratamento fisioterapêutico na Unidade Especializada em Reabilitação (UER), com comprometimento osteomuscular - CID10 - Capítulo XIII: Doenças do sistema osteomuscular e do tecido conjuntivo ${ }^{11}$.

Esses dados suscitaram a demanda por avaliações destes usuários, buscando o estabelecimento de possível nexo causal entre estes comprometimentos e o trabalho desenvolvidos pelos mesmos, bem como os resultados de ações de assistência a sua saúde, por meio de cooperação técnica interinstitucional com ações específicas para LER/DORT. Assim, o presente artigo tem como objetivo relatar as experiências de atividade grupal com 
trabalhadores com Lesões por Esforços Repetitivos/Distúrbios Osteomusculares Relacionados ao Trabalho.

\section{MÉTODO}

Trata-se de um estudo descritivo e exploratório, que apresenta experiências relativas a atividades práticas de atenção à saúde, conduzidas com trabalhadores diagnosticados com LER/DORT no período de julho a agosto de 2019.

Quanto aos procedimentos adotados, inicialmente foi necessário que os pesquisadores da Universidade entrassem em contato com a Secretaria Municipal de Saúde (SMS) do Município para apresentação dos objetivos, justificativas e metodologia do projeto, visando a autorização para a execução das ações na UER e no CEREST. A partir da autorização da SMS, este estudo foi submetido e aprovado pelo Comitê de Ética em Pesquisa com Seres Humanos da UFTM sob o parecer de número CAAE 08688818.0.0000.5154.

A Unidade Especializada em Reabilitação (UER) disponibilizou aos pesquisadores uma lista dos usuários encaminhados ao serviço, com diagnóstico de afecções osteomusculares. Esses usuários foram contactados via telefone, e identificou-se, inicialmente, quais eram trabalhadores (homens ou mulheres que exerciam atividade para sustendo próprio e/ou de seus dependentes, qualquer que fosse a inserção no mercado de trabalho, bem como afastados ou desempregados) ${ }^{12}$.

Foi agendado um horário, conforme conveniência do trabalhador (manhã ou tarde) para comparecer à UER, onde foram avaliados por avaliadores previamente capacitados. 0 diagnóstico de LER/DORT se deu a partir das avaliações dos aspectos sociodemográficos, história clínica detalhada (história da moléstia atual), exame físico detalhado, aspectos ocupacionais e sintomas osteomusculares, conforme indicado pela Instrução Normativa n⿳0 98, de 5 de dezembro de 2003, que aprova Norma Técnica sobre LER/DORT ${ }^{13}$.

Após o estabelecimento do diagnóstico, os trabalhadores foram informados sobre a proposta da atividade e foram convidados a participar voluntariamente das intervenções grupais, sendo esclarecidos a respeito de que seus dados seriam mantidos em sigilo, podendo ser utilizadas informações somente para publicação, sem a identificação pessoal dos participantes.

Portanto, foram critérios de inclusão no presente estudo: trabalhadores com 18 anos ou mais, de ambos os sexos, com diagnóstico de LER/DORT e que assinaram o Termo de Consentimento Livre e Esclarecido (TCLE).

A opção pelo desenvolvimento de práticas grupais está em conformidade com os princípios preconizados pelo SUS, sendo estas atividades cada vez mais frequentes na saúde pública, por propiciarem o compartilhamento de experiências entre os trabalhadores ${ }^{14}$, tendo em vista que os grupos funcionam como um instrumento terapêutico-pedagógico que pode servir como espaço de escuta, de troca de experiências e de reflexão, incentivando comportamentos de autocuidado em saúde por parte dos participantes ${ }^{15}$.

As intervenções psicossociais foram coordenadas pela psicóloga do CEREST e tiveram uma função terapêutica e pedagógica, abordando principalmente os seguintes temas: autoconhecimento, resolução de problemas, enfrentamento de desafios, comunicação/relacionamento interpessoal. Foram utilizadas as técnicas de dinâmica de grupo, estudo de caso, discussões grupais orientadas e confraternização. Tais técnicas se mostram úteis para a promoção da integração e coesão do grupo, para o desenvolvimento de habilidades sociais e de comportamentos assertivos, para o aumento do autoconhecimento e para adoção de postura de enfrentamento diante dos problemas. Estas foram subdivididas em três partes.

A parte inicial foi caracterizada como fase de instruções da atividade, de forma clara, colocando-se o avaliador à disposição para tirar dúvidas e delimitando-se o tempo para a realização da mesma. A segunda parte foi a de execução da atividade, acompanhando os 
participantes, estando eles próximos ou à distância. Já o fechamento da ação promoveu a reflexão crítica do participante sobre a tarefa grupal.

Um protocolo cinesioterapêutico foi desenvolvido por uma fisioterapeuta e mestranda do Programa de Mestrado em Fisioterapia da UFTM, de forma a atender a evolução dos trabalhadores, dando ênfase a alongamento e fortalecimento muscular, com exercícios isométricos e de autorresistência ${ }^{16}$.

Os exercícios de alongamento foram mantidos por 30 segundos com séries de 3 repetições, e os exercícios de fortalecimento eram realizados com séries de 10 repetições, progredindo para 20 repetições quando se atingia a metade das sessões, sempre respeitando a evolução clínica dos trabalhadores ${ }^{17}$.

Para o controle da frequência dos participantes, em cada encontro foi solicitado que os trabalhadores assinassem uma lista de presença. Ao término de cada atividade eram realizados registros descritivos de cada encontro. Esses registros foram posteriormente analisados e debatidos em conjunto pela equipe executora do projeto.

\section{RESULTADOS}

Foram oferecidas 12 atividades (encontros) para um grupo composto por seis trabalhadores com LER/DORT, duas vezes por semana, com duração de duas horas cada atividade, sendo a primeira destinada às atividades coordenadas pela psicóloga e a segunda às práticas coordenadas pela fisioterapeuta.

Tabela 1. Caracterização dos trabalhadores com LER/DORT, segundo idade, sexo, escolaridade e situação ocupacional. Uberaba, 2019.

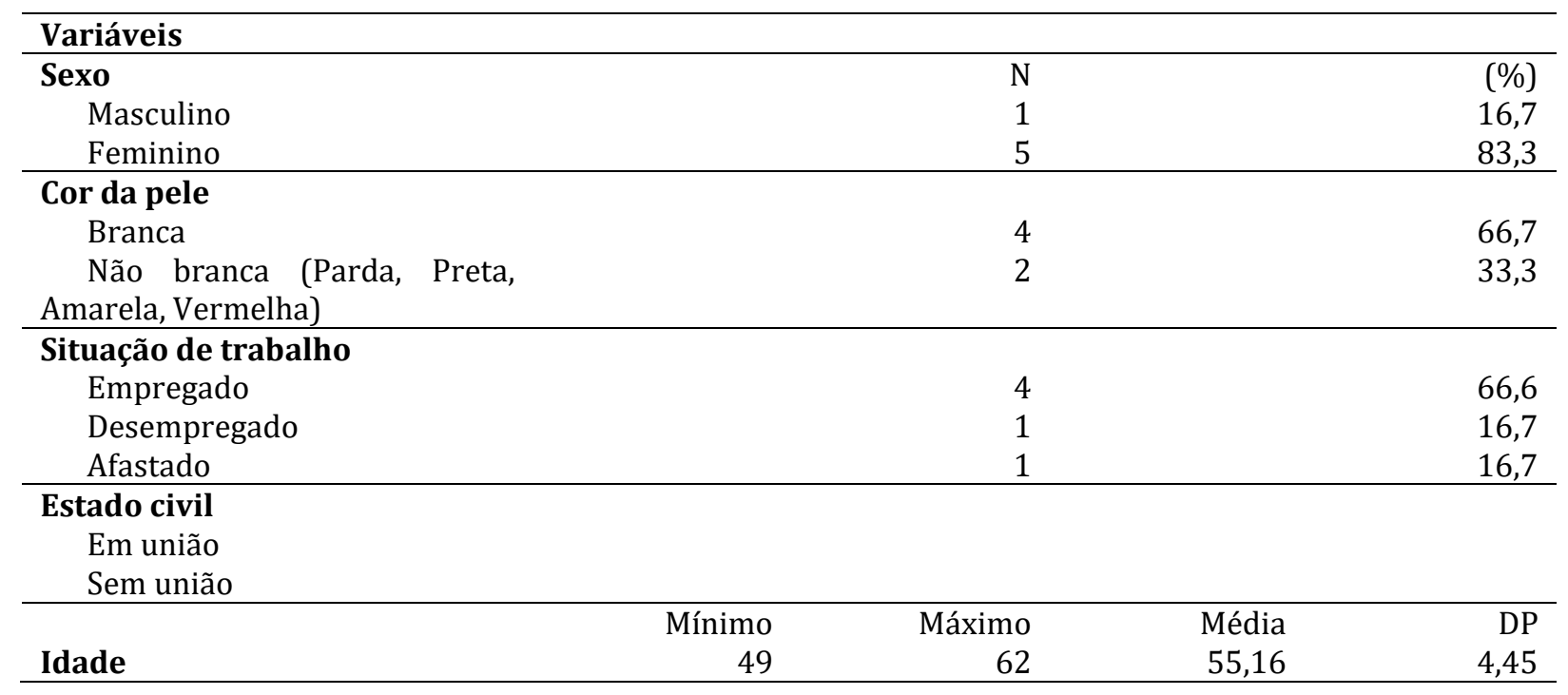

As ocupações variaram entre costureira $(n=1)$, auxiliar de cozinha $(n=1)$, cuidador de idoso domiciliar $(n=1)$, manicure $(n=1)$, vigilante $(n=1)$ e empregada doméstica $(n=1)$. Quanto ao histórico ocupacional, foi possível perceber que a grande maioria começou a trabalhar na adolescência $(n=5)$, havendo também relatos de trabalho infantil, exercendo trabalhos penosos que envolviam intenso desgaste físico e mental. A maioria $(n=4)$ está em exercício da atividade, um está afastado do trabalho pelo adoecimento e um está desempregado. Dentre os sintomas das LER/DORT destaca-se que todos relataram conviver com dores crônicas que prejudicam a realização de atividades laborais e cotidianas.

Os trabalhadores também foram identificados com transtorno mental relacionado ao trabalho, havendo diagnóstico específico de episódio depressivo $(n=5)$ e síndrome de Burnout $(n=1)$. 0 sofrimento mental desses trabalhadores com LER/DORT foi evidenciado, de forma geral, a partir da expressão de humor triste, perda do interesse e prazer nas atividades cotidianas, baixa autoestima e autoconfiança, ideias de culpa e inutilidade, bem como ideação suicida e choro com facilidade.

A Tabela 2 apresenta as descrições das atividades grupais psicossociais, bem como de seus objetivos e principais resultados identificados. 
Tabela 2. Descrição, objetivos e resultados percebidos nas intervenções grupais psicossociais. Uberaba, 2019.

\begin{tabular}{|c|c|c|c|}
\hline Encontro & Descrição & Objetivos & $\begin{array}{l}\text { Principais resultados percebidos } \\
\end{array}$ \\
\hline \multirow[t]{2}{*}{$1^{\mathrm{o}}$} & $\begin{array}{l}\text { Apresentação das características e regras contratuais das } \\
\text { atividades. }\end{array}$ & $\begin{array}{l}\text { Explicar a importância } \\
\text { do comprometimento } \\
\text { do paciente. }\end{array}$ & \multirow[t]{2}{*}{$\begin{array}{l}\text { Integração, coesão grupal, bem como a expressão de } \\
\text { sentimentos de identificação com o sofrimento físico e mental do } \\
\text { colega. }\end{array}$} \\
\hline & $\begin{array}{l}\text { Dinâmica de integração: primeiramente foi solicitado que os } \\
\text { participantes formassem duplas e obtivessem informações } \\
\text { sobre o colega. Por fim, cada participante apresentou o seu } \\
\text { colega de dupla para o grupo. }\end{array}$ & $\begin{array}{lr}\text { Reconhecer as } \\
\text { características dos } \\
\text { participantes, visando a } \\
\text { estabelecer a a } \\
\text { comunicação grupal. }\end{array}$ & \\
\hline $2^{\underline{0}}$ & $\begin{array}{l}\text { Dinâmica de autoconhecimento: os trabalhadores foram } \\
\text { orientados a representar através de desenhos/símbolos: a) } \\
\text { Como me vejo? b) Como gostaria de ser? c) Como posso } \\
\text { realmente ser? Em seguida, foram orientados a descrever o } \\
\text { significado de seus desenhos/símbolos. }\end{array}$ & $\begin{array}{l}\text { Comparar } \quad \text { a } \\
\text { autopercepção da } \\
\text { imagem corporal real e } \\
\text { ideal. }\end{array}$ & $\begin{array}{l}\text { Na expressão de como os participantes se veem, houve } \\
\text { predomínio de desenhos/símbolos relacionados à tristeza, } \\
\text { choro e apatia. Na expressão de como gostariam e de como } \\
\text { poderiam ser, houve preponderantemente desenhos/símbolos } \\
\text { relacionados a esperança e bem-estar, expressando } \\
\text { comportamentos de autocuidado e a busca pela melhora na } \\
\text { qualidade de vida. }\end{array}$ \\
\hline $3^{0}$ & $\begin{array}{l}\text { Dinâmica de resolução de problema: foi solicitado que cada } \\
\text { participante escrevesse um problema que está vivendo e que } \\
\text { não sabe resolver, sem sua identificação pessoal. Em seguida, os } \\
\text { problemas elencados foram misturados dentro de um envelope, } \\
\text { sendo depois redistribuídos para que os participantes } \\
\text { apresentassem soluções aos problemas dos colegas. }\end{array}$ & $\begin{array}{l}\text { Formular soluções que } \\
\text { envolvam a superação } \\
\text { dos problemas } \\
\text { apresentados. }\end{array}$ & $\begin{array}{l}\text { Destacaram-se predominantemente problemas de origem } \\
\text { familiar. Foi possível identificar a formulação de soluções } \\
\text { construtivas coletivas, que envolveram atitudes de } \\
\text { enfretamento, persistência, paciência e mudança de } \\
\text { comportamento. }\end{array}$ \\
\hline 4 o & $\begin{array}{l}\text { Estudo de caso: a partir da apresentação do relato de um } \\
\text { personagem fictício com sintomas de LER/DORT, foram } \\
\text { realizados questionamentos aos participantes: a) O que causa } \\
\text { as dores do personagem? b) Ele gosta do trabalho? c) O que ele } \\
\text { faz quando sente dores? d) O que ele poderia ter feito para } \\
\text { tratar as dores? }\end{array}$ & $\begin{array}{l}\text { Discutir sobre possíveis } \\
\text { formas de lidar com a } \\
\text { dor física e emocional. }\end{array}$ & $\begin{array}{l}\text { Expressão de identificação com o sofrimento do personagem, } \\
\text { tendo em vista que relataram que já desenvolveram trabalhos } \\
\text { penosos para oferecer o sustento de suas famílias, o que } \\
\text { ocasionou em uma deterioração de suas condições de saúde. }\end{array}$ \\
\hline 5o & $\begin{array}{l}\text { Dinâmica de autoconhecimento: no centro de um círculo foram } \\
\text { colocados objetos (por exemplo, acessórios, objetos pessoais, } \\
\text { utensílios domésticos). Cada paciente, foi orientado a escolher } \\
\text { um objeto com que ele se identificou em seu passado e outro } \\
\text { representando o que o paciente é hoje. }\end{array}$ & $\begin{array}{lr}\text { Comparar } & \text { a } \\
\text { autopercepção do } \\
\text { sujeito no passado e no } \\
\text { presente. }\end{array}$ & $\begin{array}{l}\text { A partir das escolhas dos objetos foram discutidas as mudanças } \\
\text { que ocorrem em diferentes fases da vida e houve o } \\
\text { reconhecimento da importância da adaptação às mudanças. }\end{array}$ \\
\hline $6^{0}$ & $\begin{array}{l}\text { Discussão em grupo orientada: os participantes foram } \\
\text { questionados sobre três assuntos que gostariam que fossem } \\
\text { discutidos. Após elencar os assuntos, a maioria do grupo, por } \\
\text { meio de votação, escolheu o tópico abordado. }\end{array}$ & $\begin{array}{l}\text { Discutir um tópico de } \\
\text { interesse do grupo. }\end{array}$ & $\begin{array}{l}\text { Foram selecionados três assuntos: religião, desemprego e } \\
\text { família. Na votação, o tema família foi o mais frequente. } \\
\text { Houveram frequentes relatos de dificuldades em impor limites } \\
\text { aos familiares e a identificação da importância de adotar } \\
\text { comportamentos mais assertivos. }\end{array}$ \\
\hline
\end{tabular}


7ํㅡㄹ Dinâmica de autoconhecimento: os participantes foram Analisar divididos em dois grupos e receberam uma folha de papel pardo. Cada grupo foi orientado a desenhar a silhueta de um dos participantes do grupo no papel pardo e representar na silhueta por meio de desenhos, símbolos ou colagens as dores físicas e emocionais do grupo.

8o Não foi realizada, tendo em vista que só uma paciente compareceu ao encontro.

9o Discussão em grupo orientada: os participantes foram questionados sobre três assuntos que eles gostariam que fossem discutidos. Após elencar os três assuntos, a maioria do grupo, por meio de votação, escolheu o tópico abordado.

10o Dinâmica de enfrentamento de desafio: foram distribuídos pirulitos e foi solicitado que os participantes formassem um círculo e segurassem o pirulito com a mão direita. Depois disso, a coordenadora orientou que os participantes estavam liberados para saborearem o doce, desde que seguissem as seguintes regras: 1 - Manter o braço direito sempre estendido e o esquerdo para trás; 2 - Fazer movimentos apenas para a direita ou para a esquerda, sem flexionar o braço.

11을 Dinâmica de avaliação de final das atividades: os participantes foram convidados a expor o aprendizado que tiveram ao longo dos encontros, completando a seguinte frase: eu aprendi que (...).

12ำ Confraternização: um café da manhã coletivo foi organizado pelas profissionais e os participantes. projeto. autopercepção de dores

físicas e emocionais.

Foi possível perceber nos desenhos a expressão de dores, especialmente nos membros superiores das silhuetas, por meio de desenhos de facas, ferimentos e amarras. Apesar de as participantes reconhecerem as dores emocionais, optaram por representar nas faces das silhuetas expressões de alegria e esperança.

Discutir um tópico de Foram selecionados três assuntos: depressão, relacionamento interesse do grupo.

com o outro e ansiedade. O tema relacionamento com o outro foi o mais frequente. Houve relatos de que os participantes se sentiam sobrecarregados por assumirem muitas responsabilidades, se preocuparem excessivamente com o outro, e a identificação da importância de adotar comportamentos mais assertivos.

Estabelecer o trabalho Foi possível perceber que a maior parte dos participantes em equipe. apresentou dificuldades em perceber que apenas conseguiriam chegar ao objetivo se um oferecesse o pirulito ao outro. Os participantes relacionaram à dinâmica o fato de que, frequentemente, tentam realizar tarefas cotidianas e laborais sozinhos, sem solicitar e/ou receber a ajuda de terceiros. Segundo eles, isso gerou esgotamento físico e emocional, contribuindo para o quadro de adoecimento.

Analisar os resultados Foram relatadas mudanças comportamentais no que se refere ao obtidos através do desenvolvimento de habilidades sociais e à adoção de uma postura mais assertiva diante de problemas.

Comemorar a evolução dos trabalhadores e propor novas atividades grupais interventivas.
Os trabalhadores, em sua maioria, ressaltaram a própria evolução e melhora nos sintomas de transtornos mentais e das LER/DORT e expressaram o interesse em continuar a participação em atividades grupais interventivas 


\section{DISCUSSÃO}

A grande maioria dos participantes era do sexo feminino. A alta prevalência de doenças osteomusculares em mulheres pode ser associada ao fato de as trabalhadoras, além de desempenharem as atividades laborais, serem as principais responsáveis pela execução de tarefas domésticas e familiares e pelo fato de as trabalhadoras ocuparem mais postos de trabalho informais, que envolvem condições de trabalho precarizadas ${ }^{18}$. Tal realidade pode contribuir também para o maior índice de transtornos mentais.

Foi possível identificar que os participantes, em sua maioria, possuíam nível de escolaridade baixo e, portanto, exerciam ocupações que, em geral, exigiam pouca qualificação. Outros estudos conduzidos no Brasil mostram a prevalência de LER/DORT em trabalhadores com baixa instrução ${ }^{19,20}$ e que exercem ocupações que exigem pouca qualificação e que são mal remuneradas, dentre elas: empregado doméstico nos serviços gerais e costureira ${ }^{20}$. Tais resultados evidenciam a necessidade de implementação de medidas de intervenção que possibilitem o fortalecimento das ações de vigilância em saúde do trabalhador que exerce atividades em que há o predomínio de movimentos repetitivos, ausência de pausas para descanso e ambientes estressantes e competitivos.

Com relação ao histórico ocupacional dos participantes, foi possível perceber que a grande maioria começou a trabalhar durante a adolescência, em trabalhos pesados e penosos. Diversos são os problemas enfrentados pelos adolescentes em seus ambientes de trabalho, dentre eles a baixa remuneração, a elevada carga-horária trabalhada e as relações de trabalho e emprego precarizadas, influenciando consideravelmente sua saúde. Contudo, mesmo tendo percepção dos problemas de saúde presentes em sua realidade, os adolescentes não conseguem cuidar adequadamente de si mesmos devido à ameaça de perderem seus empregos ${ }^{21}$.

É importante destacar que, apesar da atual condição de adoecimento físico e mental dos participantes, foi possível perceber que a maioria permanece ativa no mercado de trabalho, provavelmente porque cada sujeito reage de modo diferente às pressões em seu ambiente ocupacional, e muitos silenciam o próprio sofrimento para evitar o julgamento das chefias, a demissão e o preconceito dos colegas de trabalho ${ }^{22}$.

Entre os relatos associados ao sofrimento dos trabalhadores atendidos pelo grupo, destacam-se as dores crônicas intensas. Como a doença costuma evoluir de uma forma lenta e só é percebida pelo trabalhador quando já está em um grau avançado, esses trabalhadores a ocultam por medo de perder o emprego ou pelo receio de alguma punição ${ }^{23}$.

No entanto, esses sintomas, ao se agravarem, acabam por impedir o trabalhador de desenvolver suas atividades laborais. Assim, a dor persistente, a incapacidade física, a preocupação com a incurabilidade da doença, a perda da importância no ambiente social, profissional e familiar, as perdas econômicas e a sensação de abandono são fatores que contribuem para o surgimento de sentimentos negativos que envolvem medo, angústia, ansiedade e depressão ${ }^{24-25}$.

Desse modo, o atendimento isolado dos pacientes com LER/DORT por profissionais de diferentes áreas é insuficiente para contemplar todos os aspectos afetados de forma integrada e eficiente. Assim, a atuação conjunta da Fisioterapia e da Psicologia, com uma abordagem interdisciplinar, foi fundamental devido à complexidade e a multifatorialidade desses agravos $^{26}$.

0 presente estudo identificou que, a partir do desenvolvimento das intervenções grupais, envolvendo profissionais de psicologia e fisioterapia, foi possível perceber reações positivas dos trabalhadores com relação às atividades interdisciplinares. Os feedbacks positivos obtidos dos participantes reforçam que a atuação interdisciplinar pode propiciar um espaço de reflexão e socialização para os trabalhadores adoecidos, bem como mudar a forma como se veem e lidam com as limitações que lhes são impostas pela doença, contribuindo para a adoção de uma atitude proativa na busca pela recuperação ${ }^{26}$. 
As intervenções coordenadas pela profissional de fisioterapia identificaram que inicialmente houve dificuldade na execução dos exercícios, em função da dor. No entanto os relatos dos resultados da cinesioterapia, indicaram redução do quadro álgico, melhora do estado geral e das funções físicas, aumento da flexibilidade e ganho de força muscular.

Ao analisar as intervenções coordenadas pela profissional de psicologia, foram identificadas como queixas principais dos participantes os problemas de relacionamento com seus familiares, uma vez que, a partir do agravamento das doenças osteomusculares relacionadas ao trabalho, as responsabilidades de cada membro da família podem ser muitas vezes alteradas, implicando em mudanças ao nível de distribuição das tarefas domésticas e de outras responsabilidades familiares. As mulheres acometidas com LER/DORT mostram preocupação excessiva por não poderem fazer os serviços domésticos, cuidar dos filhos e do marido. Assim, foram frequentes os relatos durante as atividades grupais de participantes que insistiam em cumprir com os serviços domésticos, ocasionando aumento das dores e a necessidade de aumentar a ingestão de medicação analgésica ${ }^{27}$.

A partir das queixas familiares apresentadas, foi possível perceber que a falta de suporte familiar pode estar contribuindo para o agravamento do sofrimento do trabalhador, haja vista que o suporte pode ser compreendido como manifestação de atenção, carinho, diálogo, liberdade, proximidade afetiva e autonomia existente entre os integrantes da família, podendo ser identificado como um agente de proteção do indivíduo frente ao risco de doenças mentais e como agente amortecedor frente aos eventos estressantes ${ }^{28}$. Se faz importante que os serviços de saúde (em especial os públicos) promovam um maior envolvimento dos familiares no tratamento de trabalhadores acometidos com doenças osteomusculares e transtornos mentais relacionados ao trabalho.

As intervenções indicaram mudanças comportamentais no que se refere ao desenvolvimento de habilidades sociais e adoção de uma postura mais assertiva, o que pode ser essencial para manejar de forma adequada as demandas das interações sociais, servindo para alterar uma situação desfavorável para o indivíduo, já que a resposta assertiva é mais competente socialmente do que as passivas e as agressivas ${ }^{29}$.

Ademais, a abordagem grupal em saúde do trabalhador permitiu que os trabalhadores compartilhassem ansiedades e medos diante das dificuldades e que fortalecessem o vínculo e as relações de confiança entre os participantes e os profissionais que conduziram as atividades, possibilitando, portanto, a criação de estratégias individuais e coletivas que contribuíssem para o enfrentamento do sofrimento ${ }^{30}$.

A relevância para a universidade se materializou na possibilidade da realização de uma atividade intersetorial, envolvendo ensino, pesquisa e extensão, que são os grandes pilares da universidade pública no Brasil 31 .

Ressalta-se a importância da intervenção multidisciplinar e interinstitucional na saúde do trabalhador em ações que contemplem os sujeitos trabalhadores, que valorizem o potencial humano e oportunizem seu crescimento e reconhecimento, por meio da implementação de práticas inovadoras de promoção de saúde.

A parceria institucional entre o CEREST/Regional Uberaba e o curso de Fisioterapia da UFTM tem se mostrado útil à Instituição de Ensino, tendo em vista que contribui para o processo de ensino, pesquisa e extensão. Também tem sido especialmente importante para o CEREST, minimizando as dificuldades na execução de ações de promoção de saúde do trabalhador, uma vez que a equipe desse serviço conta com um número reduzido de profissionais e nem sempre consegue atender a toda a demanda apresentada por sua área de abrangência.

Dentre as limitações presentes neste relato de experiência, é importante destacar que os resultados apresentados se referem às percepções dos profissionais obtidas por meio dos relatos dos trabalhadores que participaram das atividades grupais. Dessa forma, para os 
próximos grupos, sugere-se que os profissionais envolvidos utilizem instrumentos que permitam avaliações mais criteriosas e sistematizadas da efetividade das intervenções.

\section{CONCLUSÃO}

Dentre as contribuições oferecidas por este trabalho, ressalta-se que a experiência poderá servir de base para o desenvolvimento de intervenções de abordagem interdisciplinar em outros serviços de saúde pública, especialmente em saúde do trabalhador, visando oferecer a atenção integral aos acometidos por LER/DORT.

\section{REFERÊNCIAS}

1. Alencar MCB, Merlo ARC. A saúde em troca da excelência: o sofrimento de atendentes de nutrição de um hospital público acometidos por LER/DORT. Saúde Soc. [Internet]. 2018 [citado em 23 ago 2019]; 27(1):215-26. Disponível em: http://www.scielo.br/pdf/sausoc/v27n1/1984-0470sausoc-27-01-215.pdf. DOI: http://dx.doi.org/10.1590/s0104-12902018170873

2. Freimann T, Pääsuke M, Merisalu E. Work-related psychosocial factors and mental health problems associated with musculoskeletal pain in nurses: a cross-sectional study. Pain Res Manag. [Internet]. 2016 [citado em 07 fev 2020]; 16:9361016. Disponível em: https://www.ncbi.nlm.nih.gov/pubmed/27885319

3. Melhorn JM. Epidemiology of musculoskeletal disorders and workplace factors. In: Handbook of musculoskeletal pain and disability disorders in the workplace. New York: Springer; 2014, p. 175204.

4. Brendbekken R, Eriksen HR, Grasdal A, Harris A, Hagen EM, Tangen T. Return to work in patients with chronic musculoskeletal pain: multidisciplinary intervention versus brief intervention: a randomized clinical trial. J Occup Rehabil. [Internet]. 2016 [citado em 07 fev 2020]; 27(1):82-91. Disponível em: https://www.ncbi.nlm.nih.gov/pmc/articles/PMC5306180/. DOI: 10.1007/s10926-016-9634-5

5. Sanches EN, Cutolo LRA, Soares P, Silva RM. Organização do trabalho, sintomatologia dolorosa e significado de ser portador de LER/DORT. Psicol Argum. [Internet]. 2017 [citado em 07 fev 2020]; 28(63):313-24. https://periodicos.pucpr.br/index.php/psicologiaargumento/article/view/20207

6. Marques GS, Giongo CR. Trabalhadores bancários em sofrimento: uma análise da literatura nacional. Rev Psic, Organ Trab. [Internet]. 2016 [citado em 07 fev 2020]; 16(3):220-35. Disponível em:

http://dx.doi.org/10.17652/rpot/2016.3.704

http://pepsic.bvsalud.org/pdf/rpot/v16n3/v16n3a02.pdf

7. Corrêa CR, Rodrigues CML. Depressão e trabalho: revisão da literatura nacional de 2010 e 2014. Neg Proj. [Internet]. 2017 [citado em 07 fev 2020]; 8(1):65-74. Disponível em: http://revista.faculdadeprojecao.edu.br/index.php/Projecao1/article/view/773

8. Ministério da Saúde (Br). Portaria no 1.679, de 19 de setembro de 2002. Dispõe sobre a estruturação da rede nacional de atenção integral à saúde do trabalhador no SUS e dá outras providências. Brasília, DF; 19 set 2002 [citado em 07 fev 2020]. Disponível em: http://ftp.medicina.ufmg.br/osat/legislacao/Portaria_1679_12092014.pdf

9. Barros RL. Universidade, extensão e sociedade: um estudo das ações na área da saúde na UFSCar (2004/2014) [Internet]. [dissertação]. São Carlos, SP: Universidade Federal de São Carlos/UFSCar; 2016. 106p. Disponível em: https://repositorio.ufscar.br/bitstream/handle/ufscar/8481/DissRLB.pdf?sequence=3\&isAllowe $\mathrm{d}=\mathrm{y}$

10. Deusdedit Júnior M, Fagundes EC, Brandão GR, Soares JR, Gomes GNT, Leal RS, et al. Desafios e perspectivas para a saúde do trabalhador: experiências de extensão com o Serviço de Atenção Integral ao Trabalhador. Sinapse Múlt. 2018; 7(2):105-8.

11 DATASUS. CID 10 [Internet]. [Brasília, DF: DATASUS; 201-?] [citado em 04 set 2019]. Disponível em: http://datasus1.saude.gov.br/sistemas-e-aplicativos/cadastros-nacionais/cid-10

12 Ministério do Trabalho (Brasil), Ministério da Previdência Social (Brasil), Ministério da Saúde (Brasil). A Política Nacional de Segurança e Saúde do Trabalhador [Internet]. Brasília, DF: Ministério 
da Saúde; 2004 [citado em 07 fev 2020]. Disponível em: http://bvsms.saude.gov.br/bvs/publicacoes/politica_nacional_seguranca_saude.pdf. [citado em 03 set 2019].

13 Instituto Nacional do Seguro Socil (Brasil). Instrução Normativa DC/INSS no 98 de 05 dez 2003. Aprova a Norma Técnica sobre Lesões por Esforços Repetitivos - LER ou Distúrbios Osteomusculares Relacionados ao Trabalho (DORT). Brasília, DF; 10 dez 2003. Disponível em: https://www.legisweb.com.br/legislacao/?id=75579

14. Rasera EF, Rocha RMG. Sentidos sobre a prática grupal no contexto de saúde pública. Psicol Estud. [Internet]. 2010 [citado em 07 fev 2020]; 15(1):35-44. Disponível em: http://www.scielo.br/pdf/pe/v15n1/a05v15n1.pdf

15. Dutra WH, Corrêa RM. O grupo operativo como instrumento terapêutico-pedagógico de promoção à saúde mental no trabalho. Psicol Ciênc Prof. [Internet] 2015 [citado em 07 fev 2020]; 35(2):515-27. Disponível em: http://www.scielo.br/pdf/pcp/v35n2/1982-3703-pcp-35-20515.pdf

16 Yeng LT. Reabilitação em lesões por esforços repetitivos. In: Codo WE, Almeida MCCG. organizadores. LER - Lesões por Esforços Repetitivos. Petrópolis: Vozes; 1995. p. 89-109.

17 Mendes LF, Lancman, S. Reabilitação de pacientes com LER/DORT: contribuições da fisioterapia em grupo. Rev Bras Saúde Ocup. [Internet]. 2010 [citado em 07 fev 2020]; 35(121):23-32. Disponível em: http://www.scielo.br/pdf/rbso/v35n121/04.pdf

18. Schwarz RG, Thomé CF. Divisão sexual do trabalho e impactos na saúde das trabalhadoras: adoecimento por LER/DORT. Rev Dir, Trab Polít Soc. [Internet]. 2017 [citado em 07 fev 2020]; 3(5):123-49.

Disponível

em: http://periodicoscientificos.ufmt.br/ojs/index.php/rdtps/article/download/8754/5961

19. Oliveira MM, Andrade SSCA, Souza CAV, Ponte JN, Szwarcwald CL, Malta DC. Problema crônico de coluna e diagnóstico de distúrbios osteomusculares relacionados ao trabalho (DORT) autorreferidos no Brasil: Pesquisa Nacional de Saúde, 2013. Epidemiol Serv Saúde [Internet]. 2015 [citado em 07 fev 2020]; 24(2):287-96. Disponível em: http://www.scielo.br/pdf/ress/v24n2/2237-9622-ress-24-02-00287.pdf. DOI: 10.5123/S167949742015000200011

20. Negri JR, Cerveny GCDO, Montebelo MIDL, Teodori RM. Perfil sociodemográfico e ocupacional de trabalhadores com LER/DORT: estudo epidemiológico. Rev Baiana Saúde Pública [Internet]. 2014 [citado em 07 fev 2020]; 38(3):555-70. Disponível em: http://rbsp.sesab.ba.gov.br/index.php/rbsp/article/view/608/1172. DOI: 10.5327/Z0100-0233-2014380300005

21. Torres CA, Paula PHA, Ferreira AGN, Pinheiro PNC. Adolescência e trabalho: significados, dificuldades e repercussões na saúde. Interface (Botucatu) [Internet]. 2010 [citado em 07 fev 2020]; 14(35):839-50. Disponível em: http://www.scielo.br/pdf/icse/v14n35/v14n35a10.pdf. DOI: http://dx.doi.org/10.1590/S1414-32832010000400010

22. Bittencourt LC, Belome MC, Merlo ARC. Centros de Referência em Saúde do Trabalhador, Sistema Único de Saúde e a saúde mental. In: Merlo ARC, Bottega CG, Perez KV, organizadores. Atenção à Saúde Mental do Trabalhador: sofrimento e transtornos psíquicos relacionados ao trabalho. Porto Alegre: Evangraf; 2014, p. 228-243.

23. Fundacentro (Brasil). Casos de LER/Dort ainda preocupam: Dia Internacional de Prevenção às Lesões por Esforços Repetitivos em 28 de fevereiro serve de alerta sobre adoecimento [Internet]. São Paulo: Fundacentro; 27 fev 2015 [citado em 03 set 2019]. Disponível em: http://www.fundacentro.gov.br/noticias/detalhe-da-noticia/2015/2/casos-de-lerdort-aindapreocupam

24. Fonseca AG. Lesões por esforços repetitivos. Rev Bras Med. 1998; 55(6):373-6.

25. Yeng LT, Teixeira MJ, Barbosa HF. Fisiopatologia da dor nos doentes com LER. In: Oliveira CR, organizador. Manual prático de LER-Lesões por Esforços Repetitivos. 2ed. Belo Horizonte: Health; 1998. p.191-204.

26. Paula EA, Amaral RMMF. Atuação interdisciplinar em grupos de qualidade de vida para trabalhadores com Lesões por esforços repetitivos/Distúrbios osteomusculares relacionados ao trabalho - LER/DORT. Rev Bras Saúde Ocup. [Internet]. 2019 [citado em 07 fev 2020]; 44(e5):1-10. 
Disponível em: http://www.scielo.br/pdf/rbso/v44/2317-6369-rbso-44-e5.pdf. http://dx.doi.org/10.1590/2317-6369000013119

27. Torres ARA, Chagas MIO, Moreira ACA, Barreto ICHC, Rodrigues EM. 0 adoecimento no trabalho: repercussões na vida do trabalhador e de sua família. Sanare (Sobral) [Internet]. 2011 [citado em 07 fev 2020]; 10(1):42-8. Disponível em: https://sanare.emnuvens.com.br/sanare/article/view/142

28. Souza MS, Baptista MN. Associações entre suporte familiar e saúde mental. Psicol Argum. [Internet]. 2008 [citado em 07 fev 2020]; 26(54):207-15. Disponível em: https://periodicos.pucpr.br/index.php/psicologiaargumento/article/view/19753

29. Teixeira CM, Del Prette A, Del Prette ZAP. Assertividade: uma análise da produção acadêmica nacional. Rev Bras Ter Comport e Cogn. [Internet]. 2016 [citado em 07 fev 2020]; 18(2):56-72. Disponível em: http://www.usp.br/rbtcc/index.php/RBTCC/article/view/883. DOI https://doi.org/10.31505/rbtcc.v18i2.883

30. Zavarizzi CP, Carvalho RMM, Alencar, MCB. Grupos de trabalhadores acometidos por LER/DORT: relato de experiência. Cad Bras Ter Ocup. [Internet]. 2019 [citado em 07 fev 2020]; 27(3):663-70. Disponível em: http://www.scielo.br/pdf/cadbto/v27n3/2526-8910-cadbto-25268910ctoRE1756.pdf. DOI: https://doi.org/10.4322/2526-8910.ctoRE1756

31 Presidência da República (Brasil). Constituição da República Federativa do Brasil de 1988. [Internet]. Brasília, DF, 5 out 1988 [citado em 07 fev 2020]. Disponível em: http://www.planalto.gov.br/ccivil_03/Constituicao/Constituicao.htm

CONTRIBUIÇÕES

Jéssica Carvalho Lima e Isabel Aparecida Porcatti de Walsh contribuíram na concepção, análise e interpretação dos dados, redação e revisão crítica do manuscrito. Alline Alves de Sousa, Thais de Souza Toledo, Edneia de Oliveira Salum e Camila Soares participaram na coleta, análise e interpretação dos dados, redação e revisão.

Como citar este artigo (Vancouver)

Sousa AA, Toleto TS, Salum EO, Lima JC, Soares C, Walsh IAP. Atividades grupais para trabalhadores com distúrbios osteomusculares relacionados ao trabalho: relato de experiência. REFACS [Internet]. 2020 [citado em inserir dia, mês e ano de acesso]; 8(2):317-327. Disponível em: inserir link de acesso. DOI: inserir link do DOI.

\section{Como citar este artigo (ABNT)}

SOUSA, A. A.; TOLETO, T. S.; SALUM, E. O.; LIMA, J. C.; SOARES, C.; WALSH, I. A. P. Atividades grupais para trabalhadores com distúrbios osteomusculares relacionados ao trabalho: relato de experiência. REFACS, Uberaba, MG, v. 8, n. 2, p. 317-327, 2020. Disponível em: inserir link de acesso. Acesso em: inserir dia, mês e ano de acesso. DOI: inserir link do DOI.

\section{Como citar este artigo (APA)}

Sousa, A.A., Toleto, T.S., Salum, E.O., Lima, J.C., Soares C. \& Walsh, IAP. (2020). Atividades grupais para trabalhadores com distúrbios osteomusculares relacionados ao trabalho: relato de experiência. REFACS, 8(2), 317-327. Recuperado em: inserir dia, mês e ano de acesso de inserir link de acesso. DOI: inserir link do DOI. 